\title{
Cohesion in African Narrative: A Linguistic Study of Racial Discrimination and Colonialism in A Grain of Wheat by Ngugi WA Thiong'o
}

\author{
Yahya koroma
}

PhD Researcher

\author{
Prof. Neveen Hassan Khalil \\ Faculty of Arts \\ Ain Shams University
}

\author{
Dr. Ahmed Mohamed Taha \\ Faculty of Arts \\ Helwan University
}

\begin{abstract}
This study attempts to linguistically unveil the cohesive devices in Thiong'o's novel "A Grain of Wheat" (1967). It attempts to explicate the points that relate the novel via adopting the theoretical framework of Halliday and Hasan (1976) model of cohesion. Through a close linguistic analysis of the novel in terms of diction, allusion and other aspects in which the novel relate, it is clear that the author uses cohesive devices in the composition of his literary text. The writer uses of his historical background and life experiences as foregrounds in portraying the realities faced by his main characters in the novel. The study adopts a qualitative approach and identified the use of grammatical cohesion which consists of reference, substitution, ellipsis, and conjunction, and lexical cohesion which includes reiteration and collocation. Then, the researcher outlines the number of instances, the cohesive items in data sheets. The study accounts for frequencies of occurring types of cohesion. The result shows the frequencies occurrency of the devices in order to provide the details. The study argues that the author is linguistically successful in constructing the ideas of colonialism and racial discrimination. An awareness of the continued inequalities experienced by the black race in relation to color. Racism and colonialism needs to be voiced out. Hence, this study contributes to existing issues on the construction of racism and colonialism. The study, therefore, has achieved its objective and proved the hypotheses. "Cohesion" in Afican narratives has added a new dimension to know more about the ideas of colonialism and racial discrimination.
\end{abstract}

Keyword: Cohesion, Narrative, Grammatical relation, Lexical, Cohesion, racialism Devices, Colonialism.

\section{Introduction}

This study aims to identify grammatical and lexical cohesive devices in "A Grain of Wheat"(1967) by Thiong'o. The origin of language has, however, been a matter of serious controversy. To understand a language and how it works has 
been the main concern of many linguists. A general agreement among scholars is that the primary function of language is communication. It is important in any society therefore, cannot be overemphasized. Language like religion can be powerful weapon of unification as well as a creative, descructive and driving force in the universe. Language comprehension is an interactive process consisting of background knowledge, cognitive tasks and conceptual abilities.These three deals with words; it is therefore dependant on language and its devices. Cohesive devices are basically words or phrases that ties a text. It is opined that cohesive devices aid texts to achieve its status and attain to communicative events. A written text can be viewed as a product which entails a message, content, form and genre. Halliday and Hasan (1976) state:"A text does not consist of sentences, it is realized by, or encorded in, sentence"(p.2).

This perspective of looking at text has greatly influenced discourse analysis in general. According to Crystal (1992), the term "discourse" is the sequence of sentences or utterances which seems to hang together" (p.5). As Crystal claims, a text must be organized in order to create a coherent discourse. The organization can be achieved through what is known as "Discourse forming devices" or cohesion. Cohesion as "visible network" of a text play a significant role in organizing linguistic elements into a unified whole. From the opening pages, Halliday and Hasan (1976) make their standpoint about cohesion intelligent. They propose that cohesion which primarily refers to the relations of meaning that exist within a text and define it as a text. "Cohesion happens where the interpretation of some elements presupposes the others" (p.4). Research for sometime has taken interest in two approaches that is, examining errors and syntactic features while generally ignoring the features of text that extent across sentence boundaries. One such effort that has attracted the study in writing is Halliday and Hasan's concept of cohesion in English. It is from this perspective that a textual analysis of cohesion is embarked upon in this study.

\subsection{The context of study}

Languists over the years have studied language and have actually expanded the wings of language to various levels of linguistic analysis or description such as phonology, morphology, syntax, semantics, pragamatic and discourse. There is a strata of language, the smallest one is the word, continuined by sentence and the highest one is discourse. "Discourse" is the stretches of language perceived to be meaningful, unified, and purposive. Discourse as defined used in linguistics, refer to any passage, spoken or written, of whatever length, that does form a unified whole. The spatial distance between a writer and his reader places 
certain demand on the former, one of which is explicitness, which may be achieved through appropriate choice of words and their relations. (Syal, 1994; p. 50). In writing, there is no visual or aural contact, and thus, no possibility of immediate feedback (Eggins, 1994:53).

Writers make distinct and conscious choices of lexical- grammatical items that best express the meaning they are trying to convey from the system of networks that constitute language.These are combined to form a single integrated structure, which is regarded as a text (Halliday \&Hasan, 1985: Bloor \&Bloor: 1995). Thong'o's novel "A Grain of Wheat" provides a mirror to the chaos of colonialism and racial discrimination during colonial period in Kenya, highlighting all the conflict and passions of human drama coupled with historical objectively. Through his powerful usage of language, he exhibits his personal and social vision and exposes the picture of the evolution of the African society from the colonial to the independent and the post -colonial states. Thiong'o depicts the Kenyan peasants and workers as deeply aware of the ignominious effects of capitalist exploitation and as dedicated in their opposition.

\subsection{Statement of the Problem}

A study of discourse analysis has revealed that cohesion and coherence has become one of the most salient areas in the investigation of texts (Thompson 2004, Halliday and Hasan, 1976, Brown and Yale 1983, and Hoey 1983). Thiong'o's novel signifies the most important part of his literary works. In this regard, "A Grain of Wheat" (1967), is his most debated novel due to its peculiar form, unique structure and private linguistic aspects. Ogude (1999) has commented on Thiong'o early novel, " A Gain of Wheat" -act as an important document in the history of post -colonial writing, distinguished by the urgency of its political engagement and that the subtlety of their historical gap"(p.2). Many influential critics and thinkers such as Emenyonu and Oguzie (1989:3) have praised the novel and described it as masterpiece of art.

The model presented by Halliday and Hasan (1976) realize cohesion as a nonstructural relations which mainly build up texture of text by means of cohesive ties that provide the discourse with meaning continuity. In view of that, a study of "cohesion" in the text will be beneficial and would hopefully provide significant answers about texture, discourse structure and linguistic properties, referring to discrimination and colonialism in Africa. The central problem examined in the present study is to establish whether certain features of grammatical and lexical of a text can contribute to the text being perceived as 
coherent. In the light of the above, the study examined the cohesive devices used by Thiong'o to deliver his messages to the audience about the struggle of the Kenyan people to liberate their land from British colonialism and racial discrimination. This study would broaden the scope by providing different insights on the cohesive structure in the novel and also add into the alreadyexisting data on studies in African novels. Hence, the value of this study stems from this; that new insights concerning cohesion will be arrived at that differs from the existing one.

\subsection{Aims and objectives of the study}

The study is conducted with the following aims:

1. To analyze, categorize, and describe the densities, types, subtypes, and distribution of cohesive devices found in the novel.

2. To determine how far the improper use of grammatical and lexical cohesion affects the perceived coherence of the novel, in depicting discrimination and colonialism.

3. To finding authentic textual conclusions and insinuation underlying the types and distribution of cohesive ties within the discourse.

4. To ultimately inspire future cohesive research work about colonialism and racial discrimination in Africa or in other continent from a linguistic perspective.

\subsection{Research Questions}

This study aims to answer the following questions:

1. What kinds of cohesive devices are used in the novel of Thing'o?

2. How do the grammatical and lexical cohesive devices integrate the sentences within the novel?

3. What are the dominant cohesive devices used by Thiong'o to deliver his message to the audiences about the struggle of the Kenyan people for their freedom?

4. Does the improper use of lexical cohesion affect the perceived coherence of a text? Although, the model of Halliday and Hassan (1976) is among the first taxonomies proposed for text analysis, yet one believed that it is the most comprehensive and suitable for achieving the purpose of the study. It is expected that this study might lead to the objectives of gaining a batter insight of the different usages of the cohesive ties in African narrative novel.

\subsection{Significance of the study}

The study is significant because it sticks to the following points: 
1. It will be seminal addition to the novels literature which lacks a discourse analysis based on the aspects of cohesion.

2. It will also be of benefit to people of various affiliations and interests. From a pedagogical perspective, post-graduate students of literature and linguistic will have an accessible guide about analyzing novel in terms of cohesion.

3. Teachers of English language and Africa literature will find the study beneficial since the novel has become part of discourse analysis syllabus in many universities around the World. 4. The study is hoped to be of some value to all those who have real interest in the study of text and discourse anslysis. It is also hoped that this study will open the way for future studies regarding cohesion and coherence along with the overpping between language and literature.

\subsection{Hypothesis of the study}

The study hypothesizes the following:

1. The quality of cohesive ties increases when the novelist makes an internal emphasis on certain character, theme, or imagery. Consequently, it leads to a greater percentage of occurrences.

2. There is a relationship between the density of grammatical cohesion ties on the opening paragraph of a text, and its question prompt on the one hand and the achievement level of that text on the other.

3. There is relationship between the density of each category of lexical cohesion (repetition, synonymy, opposition, inclusion, derivation) in a text and the achievement level of that text.

4. When the character referred to is a minor but of importance to the novel as whole, not only the quality of cohesive ties is reduced, but it would spread over broader span of the text.

\subsection{Scope and limitation of the study}

The present study is constrained to the following limits:

1. The study limits to Halliday and Hasan's model of cohesion in English (1976) and their later views about its notion and the taxonomy of its categories and subcategories.

2. Studying Thiong'o literary style and exploring its non -linguistic cohesion types. Analyzing the novel linguistic cohesion in terms of the proposed model.

3 . Testing the validity of the hypothesis and exhibiting the obtained results and conclusions. 


\section{Review of Literature}

\subsection{Introduction}

This section of the study reviews the related literature on both language and African narrative texts to find out how Thiong'o uses cohesive devices to deliver his message to the audience about colonialism and racial discrimination in "A Grain of Wheat"(1967). This includes discussion of issues related to the subject of the study: definition of language by linguists from different point of view, the concept of text and texture, colonialism and its impacts, racial discrimination, and resistance of the Kenyan native people against exploitation by the British colonizer during the colonial era in Kenya, East Africa. It also includes the previous studies of cohesion by scholars.

\subsection{A brief definition of language}

This section will focus on the definition of language by different linguists. Language as a tool has been used creatively by Thiong'o in most of his works to depict many ideas. Language is essentially a means of communication among the members of a society. In the expression of culture, language is a fundamental aspect. It is the tool that conveys traditions and values related to a group identity. The only means of understanding the great mind of the past is by studying the contemporary written document of the time. Halliday (1976) definition of language states that: "Language is interpreted as a system of meanings, accompanied by forms through which the meaning can be expressed" (p: 96). Beyond the grammar and lexis of language, understanding the mechanism for how text is structured is the basis for his work. In a broad sense, all language creates series of texts, whether written or spoken, which constitutes the only reality available to us. Bloch \&Trager(1942) argue that " Language is a system of arbitrary vocal symbols by means of which a social group cooperates" (p: 5). Moreover, Hall (1968) in his Essay on language, states that language is "The institution where by which humans communicates and interacts with each other by means of habitually used oral-auditory arbitrary symbols"(p:158). On the other hand, Robins (1964) argues that "Languages are infinitely extendable and modifiable according to the changing needs and conditions of the speaker"(p: 14). Chomsky(1957) states that "language is a set of (finite or infinite) of sentences, each finite in length as set of physical pattern that are arbitrarily combined to make the communication process effective" (p:13). From Chomsky's definition, it's obvious that language consists of several elements each with a different way of operation but combined together to produce unlimited constructions. Therefore, to Chomsky, language is 
functional element used by human for the purpose of communication, and from the perspective of language by Sapir (1921), language communicates ideas, emotions, thoughts, and desire which, when put down in a literary text, it referred to as literature (p.8).

\subsection{Text}

Linguists have been concerned, for a long time, within the scope of text linguistics, with investigating the principles of connectivity which bind the text and view it as a unified whole rather than a set of unrelated sentences thrown at random. It is widely believed that any piece of language, spoken or written, is composed of a set of clues or cues (Gee, 1999:88). That is to say, there must exist some devices that the speaker or writer utilizes to design craft or shape their texts. These devices function as a guide to the listener or the reader to follow their participants. A text should be ultimately viewed as a set of connected threads, if you pull any one of them you get all the others (ibid). In other words, any text should hand together in a way that ensures an easy and smooth flow of thoughts. Halliday (1994) maintains that:

"In order to construct a discourse we need to be able to establish additional relations within the text $\{\ldots\}$ relations that may involve elements of any extent, both smaller and larger than clauses, from single words to lengthy passages of text; and that may hold across gaps of any extent, both within the clause and beyond it, without regard to the nature of whatever intervenes. This cannot be achieved by grammatical structure; it depends on a resource of a rather different kind. These non-structural resources for discourse are what we referred to be the term cohesion"(p.309).

\subsection{Texture}

The concept of texture expresses the property of being a text. Texture distinguishes a text from other units. It is made by the presence of the meaning cohesive relations within the text. Typically, a text extends beyond the confines of structural relations, but texts cohere by the virtue of texture provided by nonstructural ties (Halliday and Hasan, 1976:67). Hasan (1989: 70) argues that texture is the source of textual unity. It is like structure in having relevance to the context of situation. It is another source of language continuity and has certain aspects: 1 . Texture is manifested within the passage by certain semantic links. 2. It differs from the text structure phenomenon. The property of texture is related to the listener's perception of coherence.

\subsection{Colonialism}


According to "Standard Encyclopedia of Philosophy" 2006, Colonialism is defined as "the building and maintaining of colonies in one territory"(p: 65). Between about 1500 and the early 1900s, many European countries looked beyond Europe for resources that they could control and trade in. They took over many parts of the World as "Colonies" and introduced their own systems of government, economic organization, religion and education. By the 1900s, the British Empire ruled over colonies in North America, Australia, India and Africa. Like so many other areas, East Africa was opened to colonial domination by Britain with the building of railroad, from Kenya to Cape Town in South Africa (Marshall, 1968:p.42). The view of Thiong'o Kenya's most prominent writer and dissident, on the dialectical relationship between aesthetics and politics have established his work among the most important to come out of Africa.

\subsection{Racial Discrimination in "A Grain of Wheat" (1967)}

This part examines racial problems during the colonial period in Kenya. Thiong'o in this novel concluded that the establishment of Kenya as a White colony brought up it with racial discrimination, against the natives Kenya people during the colonial era. The White setters established and maintained racial discrimination with the idea of retaining their position of superiority. (Norman leys, 1944; p. 154). In Kenya the white minority entrusted with the above policy which placed the country upon a path that led to a racial war was fought to restore equal right policy. The disregard of the policy of equal rights and the practice of racial discrimination took place without the sanction of parliament. The British public was largely unaware of it. In the 1940s almost fifty years after taking over Kenya, the British were still talking of their empire as if it were based on free and equal opportunity for all (Norman ley 1944;p. 22).

\section{7 previous studies}

The following section details the qualitative literature considered to be the most relevant to the present study. There have been many empirical studies conducted to establish the significance of cohesion in wtrtten texts. These studies have often had different specific aims and areas of focus. Most of the studies listed here have aimed to provide insight into the writing quality of authors in various text books. It is expected that linguistic which assesses the influence of cohesion on writing quality is relevant to this study.

2.7.1 Jabeen, Mehmood and Lqbal (2013) attempts to explore how cohesive devices particularly referenc, substitution and ellipsis, contributes to meaning in 
"Chekhov's The Bear". The paper touches on three cohesive devices that are used as the instruments of analysis. Providing barely any examples on reference, substitution and ellipsis is a major drawback since these three compose the model used for analysis the selected literary work. The purpose of the study, which is to establish the links between cohesive devices and coherence is hardly achieved. The study merely explains the selected texts from the play, identifies instances of cohesive devices, and yet fails to create the link between the meaning of the text and the use of the cohesive devices. For example, the paper claims that the instances of clausal substitution used in the play indicate lack of respect, without providing any backgrounding, social or textual, to support their claims, which make them subjective ones.

2.7.2 Kur (2015) analyses cohesive devices in Keat's "Ode to autumn", basically using the model of Halliday and Hasan (1976). The study sets its aim as to show how cohesive devices link the various parts of the text together, which is what cohesive devices have for long been acknowledged to do. In fact, the absence of a literature review section that addresses the previous studies of cohesive devices in pieces of literature makes it hard to recognize the contribution of this paper.

2.7.3 Yde and Spoelders (1985) carried out an investigation to determine, amongst other things, the degree of cohesiveness shown in texts of beginner and advanced writers and the kind of cohesive devices used by beginner and advanced writers. Focussing on narrative writing, Dutch-speaking students who were enrolled at elementary school. The first sample they selected consisted of 14 children aged between 8 and 9 years old, the second sample of 14 children aged between 10 and 11 years old where they anticipated that the children would be more aware of the difference between speech and writing (1985:409). They used Halliday and Hassan's (1976) classification of cohesive devices, listing under lexical cohesion both reiteration and collocation.

Their finding showed that although lexical cohesion was the predominant type of cohesive devices used in the texts of both the young and older children, the majority of ties were of repetition. Synonyms were rarely used. They nevertheless conclude that cohesive skills are important skills in writing and they can be taught to improve writing. Despite this, they discovered that the older children used cohesive ties more effectively to produce more compact writing.

2.7.4 Witte and Faigley (1981) in an effort to explore what internal characteristics of student eassys distinguish those ranked high from those 
ranked low in terms of writing quality, applied Halliday and Hassan's(1976) cohesion taxonomy to five high -rated and five low-rate essays. They discovered that high -rated essays contained a higher density of cohesion than did the lower -rated once and that two thirds of the cohesive ties used in all essay were lexical. They found that lexical collocation ties best distinguish writing ability (Witte and Faigley (1981:199) conclude that writing quality incorporates factors other than cohesion density. These factors which are also conditions of coherence include the writer's purpose. The reader's knowledge and expectations and information to be conveyed (1981:202).

2.7.5 McCulley (1985) conducted a study to explore the relationship among certain of Halliday and Hassan's (1976) cohesive devices and primary -trait assessments of writing quality and coherence to establish whether specific textual features of writing affect judgement of coherence and quality of writing. To do this, he analysed 493 persuasive essays written by 17 year-olds for an authoritative audience. He found that the lexical cohesion relation of synonym, hyponym and collocation contributed most to the judgement of coherence and writing quality (1985:278), but concluded that textual features do not entirely account for coherence judgements. Coherence consists of more than relationships of cohesion. This research is not the first study analyzing cohesion in narrative text. There has been a lot of studies investigating cohesion in narrative texts. There are similarities between this research and the related studies conducted by various scholars. First, the study investigate the cohesive device consisting of grammatical and lexical cohesion. Second, it adopts Halliday and Hassan (1976) model of cohesion.Third, the study is conducted in English language, not in French or German language. Therefore, the method of the previous studies can be applied to this study. The principles of grammatical cohesion, reference, substitution, ellipsis, conjunction, and lexical cohesion, reiteration and collocation presented by Halliday and Hassan (1976) applied in the previous studies and also used in this research. The aim is to highlight the significance of cohesive ties in the texts which form its semantic base.

\section{THE THEORETICAL FRAMEWORK OF THE STUDY}

\subsection{Introduction}

This section operates within Halliday and Hasan's theoretical framework of the cohesive model, as it appears in their seminal work of cohesion in English (1976), and in their later works particularly their view about the grammatical and lexical cohesion. It investigates the dominant cohesive devices used by Thiong'o about colonialism and racial discrimination as manifested in "A Grain 
of Wheat"(1967). It mainly focuses on the two major divisions of cohesion: grammatical and lexical cohesion. English language has linguistic resources the function of which is to link an element of language with what has gone before or what follows in a text (Bae 2001:55). All grammatical units of any size, sentences, clauses, groups and words can be linked, and so all of them may have cohesive function.

\subsection{Halliday and Hasan (1976) Model of cohesion}

Halliday and Hasan's (1976) model of cohesion was adopted as the most suitable method for analyzing "A Grain of Wheat". This is because they (Halliday and Hasan) gave a detailed insight into the study of cohesion. Systemic Functional Linguistics grew out of the words of J.R. Firth, a British linguist of the 30's, 40's and 50's (who was influenced by Malinowsky), but was mainly developed by his student M. A. K. Halliday. He developed the theory in he early sixties (in a seminar paper, Halliday 1961). Systemic Linguistics according to Halliday is an approach to linguistics that considers language as a system that cannot be dissociated from meaning. It is considered "functional" rather than "generative" in linguistic orientation.

\subsection{Cohesion in English}

Cohesion is one of the linguistic elements that preserve the consistency and association of words within sentences throughout a passage. It is a network of lexico-grammatical relations that connects various elements in a text and makes it a meaningful one by using different linguistic markers. Halliday and Hasan's words (1976): "cohesion occurs where the interpretation of some elements in the discourse is dependent on that of another. The one presupposes the other in the sense that, it cannot be effectively decoded except by recourse to it. When this happens, a relation of cohesion is set up, and the two elements, the presupposing and the presupposed, are thereby at least potentially integrated into a text"(p.04).

\subsection{Types of Cohesion}

According to Halliday and Hasan's model (1976), cohesion is classified into two broad types: grammatical and lexical. While the grammatical type is realized by various grammatical devices used to make relation among sentences more explicit, the lexical one is established through the structure of vocabulary by relating words in terms of their meaning.

\subsection{Grammatical cohesion}

Halliday and Hassan (1976) classify the categories of grammatical cohesion into four types: reference, substitution, ellipsis, and conjunction. According to 
Halliday and Hasan (1976) the first types are purely grammatical while the fourth category of conjunction occurs in between the grammatical and lexical classification, but it is closer to the former. Each one of these categories has three sub-divisions according to the grammatical items used in realizing them.

\subsection{Reference}

Halliday and Hasan (1976) describe reference as referring to the relationship between two linguistic expressions (p.31). It can be regarded as the relationship between pronouns and their antecedents. Halliday and Hasan (1976:33) separate between two kinds of reference, that is exophora and endophora reference. Exophora reference relates to something outside the text in question whereas endophora reference refers to elements within the text.

\subsection{Exophoric reference}

Exophoric reference requires the reader to infer the interpreted referent by looking beyond the text in the immediate environment shared by the reader and writer. For example in the sentence:"For he is a jolly good fellow. And so say all of us" (Halliday and Hasan, 1976, p-17-32).

. The pronoun (he) does not refer to any element in the text, but rather to an element that occurs in the context of situation. Though the text does not make it clear who "he" is, participants are able to identify the referent by the context in which the situation occurs.

\subsection{Endophora reference}

The second major category of reference is endophora. It is considered a textual reference which connects the main part of the text together. Andophora as explained by Halliday and Hasan (1976) is the umbrella term that encompasses anaphoric and cataphoric references.

Example of endophora reference: "Wash and core six cooking apples. Put (them) into a fireproof dish" (Halliday and Hasan, 1976:p. 2-18).

In the above example the personal pronoun (them) in the second sentence refers back to "six cooking apples"in the first sentence.

\subsection{Anaphoric reference}

For cohesion purposes, anaphoric referencing is the most relevant as it "provides" a links with a preceding portion of the text (Halliday and Hasan, 1976:51). Anaphoric reference is interpreted only by relating an item to something else a referent identical to it and preceding it in the text. Example: Amy went to the party. She sat with Sara.

(She) refers back to (Amy), therefore, (she) is an anphoric reference. 


\subsection{Cataphoric reference}

Cataphoric reference refers to any reference that "point forward" to information that will be presented later in the text. Example: As soon as he arrived, Mile visited his parents. $(\mathrm{He})$ is a cataphoric reference that looks forward to Mike. Halliday and Hasan (1976:37) have categorized reference into three main groups, that is, personal, demonstrative and comparative reference.

\subsection{Personal reference}

Personal reference is a reference by means of function in the speech situation, through the category of person (Halliday and Hasan 1976:43). The cohesive device of personal reference is of three classes: personal pronouns, possessive determiners, and possessive pronouns. These three categories have no general identity within the traditional grammar since they are all placed under the category of person (Halliday and Hasan, 1976:43). To exemplify: Italians came from a long way off to look up at the war monument; it was made of bronze and glistened in the rain, (Hem 159). Here personal reference is established with the personal pronoun it which refers back to the noun phrases the war monument and forms a cohesive tie. The use of cohesive linguistic devices contributes to the reader's feelings that the two sentences go together fairly well and from a single text.

\subsection{Possessive reference}

Many Scholars do not list possessive reference among the subtypes of reference. However, while analyzing the peculiarities of cohesive devices in English, possessive pronouns present interesting cases and constitute a separate and independent group of personal reference. The possessive pronouns are variants of the personal pronouns. The possessive pronouns differ from other personal reference items in one respect. i.e. "a personal pronoun functions as an independent element and is head of the noun phrases, whereas possessive pronoun functions as a modifying element of a noun phrase" (Verikaite 1999:49). As a sequence, possessive pronouns require two references, a possessor and a possessed whereas other personal pronouns require one. For example: "Can you have Mary a programmer? Hers has got lost?" (Halliday and Hasan 1976:55) In the latter instance, the possessive pronoun "hers" is doubly anaphoric because it presupposes Mary by reference program by ellipsis. The anaphoric possessive pronouns tend to occur in close proximity with the textual referent: therefore, possessive as "referential items express either the relationship of "ownership" between two lexical items (Buitkiene, 
2005:18). In many cases the function of possessive is to reinforce the relationship between two lexical items.

\subsection{Demonstrative reference}

According to Halliday and Hassan (1976:57), demonstrative reference is defined as a form of verbal pointing. The referent is identified by locating it on the scale of proximity. It uses words such as: this, that, these, those, here, and there. For example:
a. Pick these up!
b. Leave that there and come here!
c. Look at the flowers!
d. Don't go: the train's coming (Halliday and Hasan, 1976:58).

The demonstrative "this, these, and 'here' indicate proximity to the speaker. Where "that' those' and "there" indicate distance from the speaker. The definite article "the" is used exophorically, i.e. the situation clarifies what the referent is. In examples (c) and (d), the meaning of definite article "the" is clear as the context of situation specifies the referent.

\subsection{Comparative reference}

Halliday and Hasan (1976:37) suggest that comparative reference contributes to textual cohesion by setting up a relations of contrast expressed by such adjectives as same, identical, equal, adjective in a comparative degree, and adverbs, such as identically, likewise, so, such, etc. comparative reference is categorized by Halliday and Hasan (1976) into two sub-categories: general, and particular. While the general sub-category expresses resemblance between things with regard to identity, similarity, or difference, the particular one demonstrate comparability between things in terms of quantity or quality.

\section{Example of general identity:}

We have received exactly the same report as was submitted two months ago.

Similarity: The candidates gave three similar answers.

Example of Particular quantity and quality: There were twice as many people there as last time (quantity).

There are more things in Heaven and Earth, Horatio, than are dreamt of in your philosophy (quality).

Example of difference: A: would you like these seat? B: No, I'd like the other.(Halliday and Hasan,1976).

\subsection{Substitution}

The second device the speakers or writers use to tie different parts of utterances to create sentences is substitution. Halliday and Hasan (1976) describe 
substitution as the replacement of one item or items by another (pp.88-89). There are also different types of substitution which are called nominal substitution (replacement of a noun by "one, ones, same", verbal substitution (replacement of a verb by "do") and clausal substitution (replacement of a clause by "so", not"(Halliday and Hasan 1994: 90f). For example: "Which icecream would you like? "I would like the pink one". "One" is used instead of repetition "ice-cream" (Halliday and Hasan (1976).

\subsubsection{Nominal substitution}

This sort of substitution is often found by using "one" or "ones" as the function of head in the nominal group and replaces only items that have an identical aspect. These two items are used to presuppose (+ certain/ a particular) noun that has the function of head, but it does not carry the same modifiers of the replaced item. It carries the information that distinguishes the instance in which it occurs to the related one through cohesion (Halliday and Hasan, 1976: 91-93). For example Halliday and Hasan (1976) state: If only I could remember where it was that I saw someone putting away the box with those candles in I could finish the decorations now: - you mean the little coloured once? (P: 91). Nominal substitution: substitutes the noun in the sentence. Commonly, the substitutes used are one/oncs. For example 'The car's price is too expensive. I can only buy the cheaper one. The "one" used in the sentence substitutes the car mentioned in the previous sentence.

\subsubsection{Verbal substitution}

Verbal substitution operates as head of a verbal group (e.g. do, does). For example: He never really succeeded in his ambitions. He might do, one felt, had it not been for the restlessness of his nature (Halliday and Hasan 1976:113). Verbal substitution substitutes the verb in the sentence. Commonly, the substitutes used are do/does. For example: You think Sue already drink. I think everybody does (Halliday and Hasan, 1976). "Does" used in the sentence substitutes the verb "drink" mentioned in the previous sentence.

\subsubsection{Clausal substitution}

In this type of substitution, what is presupposed is not an element within the clause (so, not). For example: If you agree on that, so is she. "So she is" used in the sentence substitutes the clause "agree on that" mentioned in the previous sentence (Halliday and Hasan, 1976). Is there going to be an earthquake? - It says so (Halliday and Hasan 1976:130). 


\subsection{Ellipsis}

Halliday and Hasan (1976) define ellipsis as "something left unsaid" (p.142). However, it does not mean that what is unsaid is not understood. Ellipsis as a type of cohesive relation is very similar to substitution. While substitution referred to the placement of one textual element by another, ellipsis is simply characterized by "the omission of an item"(Halliday and Hasan 1994:88). The process can, therefore, be "interpreted as that form of substitution in which an item is replaced by nothing"(Halliday and Hasan; 1994: 142).

Halliday and Hasan (1976) state:

The tiny creature -called peewee -is fully grown and yet (the) measure less than one inch in length, (the) weighs less than one ounce and (the) is no higher than a 50p piece (P: 131). The pronoun "he" is supposed to be written in the series of sentences above, but instead it is omitted. The omission of the pronoun is called ellipsis, it is allowed as long as the meaning of the sentence is still the same and understandable. Halliday and Hasan (1976) list three types of ellipsis: nominal, the omission of head nouns in a nominal group; verbal, an ellipsis within the verbal group; and clausal, the omission of a clause.

\subsubsection{Nominal ellipsis}

Nominal ellipsis is ellipsis within the nominal group. The structure, as Halliday and Hasan (1976) claim is that of Head with optimal modification; the modifying elements include some which proceed the head and soon some which follow it, referred to as pre-modifier and post-modifier. Head is usually a common noun, proper noun or pronoun expressing the thing. An elliptical nominal group clearly requires that there should be available the information necessary for filling it out. The source of information usually is proceeding a nominal group that is elliptical presupposes a previous one that is not, and it is therefore cohesive. Any nominal group having the function of head filled by a word that normally functions within the modifier is an elliptical one. Nominal ellipsis therefore involves the upgrading of a word functioning as deictic, enumerative, epithet, classifier or quantifier from the status of modifier to be status of head. For example: Four other oysters followed then, and yet another four....The second four, which is a numerative and therefore is a modifier, is upgraded to function as head.

3.16.2 Verbal ellipsis: Verbal ellipsis is ellipsis with the verbal group. An elliptical verbal group presupposes one or more words from a previous verbal group. Technically, it is defined as a verbal group whose structure does not fully express the systematic feature example: (A). Have you been swimming? Yes, I 
have. (B). what have you been doing? Swimming (Halliday and Hassan, 1976:167). The two verbal groups in the answers "have" (in yes I have) in (a) and swimming in (b), are both the instances of verbal ellipsis. Both stand for "have been swimming", and there is no possibility of "filling out" with any other items. The example (b) could be interpreted only as "I have been swimming" and it could furthermore, be replace by "I have been swimming", since as in all types of ellipsis, the full form and the elliptical one are both possible.

\subsubsection{Clausal ellipsis}

Clausal ellipsis in English, considered as the expression of the various speech functions, such as statement, question, response and so on. Clausal ellipsis refers to ellipsis of a whole clause or part of a clause, as in the following example :(A). Have you ever been to the Great wall? (B.). Yes, twice, (= I've been to the Great wall twice). Some elliptical constructions presuppose some elements not within the text but in the context of situation, as in the following example: (A). Better today? (Are you better today?) (B). Much better. (= I'm much better today). (Halliday and Hassan 1976).

\subsection{Conjunction}

As a cohesive category, conjunction possesses both of the grammatical and lexical aspects of the lexicogrammar, but is closer to the grammatical in identity. Conjunction is not an anaphoric relation and this what distinquishes it from other categories. Conjunction items are not self-cohesive, but cohesiveness is attributed to their own senses. Moreover, they are not phoric relations that presuppose other items in the discourse (Halliday and Hasan, 1976: 226). There are four types of conjunctions based on Halliday and Hasan (1976) which are additive, adversative, causal, and temporal.

\subsubsection{Additive conjunction}

Additive Conjunction acts to structurally coordinate or link by adding to the presupposed item and is signaled through, and, also, furthermore, additionally etc. Conjunction has a function to connect two clauses that contain different information. An, or, nor, furthermore, besides, that is, other words, etc. (Halliday \&Hasan, 1976:p.44). Example: For the whole day he climbed up the steep mountainside, almost without stopping. And in all this time he met no one (ketabi, 2012:364). Additive conjunction may act to negate the presupposed item and is signaled by nor, and...not, either, neither, etc. The following conjunctions are used to express the additive relationship. 1. He's a student of English as well as a deeply religious man. 2. My neighbor's dog is 
not only large but also unfriendly 3 . She drove neither slowly nor carefully. 4. He's tall, rich, and handsome. As noted from the examples, conjunctions can often be used to link two (or more) parallel parts of speech. In the examples above, the conjunction "as well as" in the first sentence links two noun phrases. In the second sentence "not...but also"links two adjective. In the sentence "neither...nor" links two adverbs. And in the fouth sentence, "and" links the second and the third adjective of the list tall, rich, handsome. Additive conjunctions are embodied in the form of conjunction.

\subsubsection{Adversative conjunction}

Adversative conjunctions are the term proposed by Halliday and Hassan, and adopted by Murcia and freeman. The basic meaning of adversative is contrary to expectation. The expection may be derived from the content (Halliday, 1976). From this meaning, one can assume that the conjunctions are used to contrast. The concept is the root. However, some linguists have different term to define the concept. Guy Cook (1989) calls contrast conjunctions, Swales and Fear (2008) name linking words, Oshima and Hoque (2006) name opposite transitional signals, and Brown et al (1984) name constrative coordinating work. Halliday and Hassan (1976) stated, adversative conjunctions denote contrast and comparison indicating what is "contrary to expectation" (p.250).Conjunction connects two different clauses each is in contrast to another by using these words such as but, though, yet, however, on the other hand, in either case, etc. Example: All of the figures were correct, they'd been checked. Yet the total comes out wrong. All this time Tweedledee was trying his best to fold up the umbrella, with himself in ...but he couldn't quite succeed... (Halliday \& Hasan 1976).

\subsubsection{Causal conjunction}

Clausal relations are expressed by simple forms (so, thus, hence, therefore, consequently, accordingly) and a number of expression (as a result of that, in consequence of that, because of that) which are regularly combined with initial"and"(... and the consequence of his behavior was terrible). They occur under different positions, for instance "so" occurs only initially unless following "and" (i.e. They argued so he felt really bad); "thus" like "yet", occurs initially or in the first part (i.e.yet he didn't say anything); "therefore' has the same potentialities as "however", that is, intial position and between commas(i.e. They left early in the morning. However, she didn't want to leave her city). Example: ... she wouldn't have heard it at all, if it hadn't come quite close to her 
car. The consequence of this was that it was ticked her ear very much... Halliday and Hasan, 1976).

\subsubsection{Temporal conjunction}

Halliday and Hasan (1976: 261) indicate that temporal conjunctive is identified with the presence of two successive sentences whose contents are time sequenced. Its function is to give a sequence or a time for something to happen. They are: then, until then, afterward, subsequently, etc. In a sentence it can be like in the following: The weather cleared just as the party approached the summit. Until then they had been seen nothing of the panorama around them (Halliday \&Hasan 1976).

Halliday and Hassan (1976:261) state "the temporal relation may be made more specific by the presence of an additional component in the meaning, as well as that of seccession in time". For example: "Today I will go to my groundmother's house, and next week I will go to my uncle's house". The utterance "next week" is temporal conjunction because it indicates the sequence of time. Another example: "It is always happens" said the Gnat. After this, Alice was silent for a minute or two, ponding (Halliday and Hassan, 1976:261). The utterance "after this" is a temporal conjunction.

\subsection{Lexical cohesion}

Lexical cohesion is a linguistic device that is used to create unity among sentences. It is generally understood as "the cohesive effect that is achieved by the selection of vocabulary"(Halliday and Hasan, 1994:274). Halliday and Hasan (1976) divide lexical cohesion into two types: Reiteration and Collocation. Reiteration is achieved either through the repetition of the same lexical item or a lexical item that is different but systematically related to the first one. According to Halliday and Hasan (1976) reiteration refers to "a form of lexical cohesion which involves the repetition of a lexical item, at once end of the scale; the use of a general word to refer back to a lexical item, at the other end of the scale; and a number of things in between-the use of synonymy, near synonymy, or superordinate"(p. 276).

\subsection{Repetition}

Repetition is described by Hallday and Matthiessen (2004) as the most direct form of cohesion. Repetition occurs when a lexical item is repeated for instance, the word "bear" in the following example. Algy met a bear. The bear was bulgy (Halliday and Matthiessen 2004:571). The word "bear" in the second sentence refers back to the first one. It links the two sentences together. Repetition is a feature of language which makes the production of language 
easier to manage and more efficient. Repetition helps in facilitating the speaker's ability to formulate language fluency as it gives them a chance to think what he is going to say next. Repetition does not only make the process of production easier but also facilitates comprehension to readers by establishing a less dense discourse.

\subsection{Synonymy}

Synonymy is another type of elaboration where two lexical items have the same or similar meaning. For example: He was just wondering which road to take when he was startled by a noise from behind him. It was the noise of trotting horses ...He dismounted and let his horse as quickly as he could along the right -hand road. The sound of the cavalry grew rapidly nearer... (Halliday and Matthiessen (2004:573). In the example, an instance of synonymy is established between the lexical items "noise" "sound" "horses" and "cavalry" where they have the same meaning. Synonyms make text much more captivating and help avoid dull text. It helps provide image in the mind of the reader and help avoid boring and repetitive text.

\subsection{Antonymy}

Another relation of lexical cohesion is antonym. It relation occurs when two lexical items have an opposite meaning. For example: He felt asleep. What woke him was a loud crash (Halliday and Matthiessen, 2004:574). In the example, the two lexical items "asleep" and "woke" have an opposite meaning, therefore; a relation of antonym is established between the two terms. Antonymy helps achieve textual cohesion. It reveals the opposition and the unity of objects in languages.

\subsection{Hyponymy}

The term hyponymy is used when a lexical item which represents a class of thing is followed by a sub-class or vice versa in which the sub-class is succeeded by the super class. For example: You take over a main line like the Great central and a few branch lines that run off from it, you electrify it, and then instead of running trains as they're run at present as public vehicle you hire out small trains to individual drivers(Halliday and Matthiessen, 2004:574). The example presents an instance of hyponymy relation where the subclass "trains" is succeeded by the superordinate term "vehicles".

\subsection{Meronymy}

A relation of meronymy is established either a lexical items is presented as a whole followed by a lexical or a group of lexical items regarded as a part of 
that lexical or, when the sequence is reversed in which the part is succeeded by the whole. Example: Elfrida had a beautiful little glass scent -bottle. She had used up all the scent long ago; but she often used to take the little stopper out... (Halliday and Matthiessen, 2004:576). In the example, the term "stopper" is part of the whole "bottle", hence a relation of meronymy is achieved

\subsection{Collocation}

Collocations are lexical "items that regularly co-occur" Halliday and Hassan (1976, p: 284) and by doing so create cohesion within a given text or discourse. It is considered to be the mechanism that provides cohesion to the text. Moreover, it represents a key constituent to the lexical of any language (Halliday and Hasan 1976, p, 283). In etymological term "collocation" is derived from "collocate", which means to place together. Halliday and Hasan (1976) for example complementary: boy_-girl—stand up---sit down. Moreover, collocation is regular combination of words in which to fulfill the meaning, these words must be appeared together such as black coffee instead of thick coffee and drink medicine instead of eat medicine. Pairs of words that have opposite meaning for example: basement=roof, road=rail, red=green. 2) Pair of word two words drawn from the same series. For example: dollar=cent, North=South, Colonel=Brigadier. 3) Part of the whole. For example car=break, fox=lid. 4) Part to part. For example: mouth=chin, verse =chorus (Halliday and Hasan 1976).

\subsection{Narrative text}

Narration is defined as the accounting of an event or sequence of events, real or invented. Yet, fludernick (2006) states that "Narration' and Narrative act" underlie the telling of a story by a narrator, who may address a Narratee (p.157). To be specific, narrative texts aim to make the audience think about the issues, teach them a lesson, and excite their emotions (Anderson and Anderson, 1998:3). People are close to this form of texts rather than other forms since the topics are related to daily life such as love, friendship, conflict, war and the like (McNamara, 2011: 231-232).

According to Anderson and Anderson (1997), there are steps for conducting narrative texts, namely: 1. an orientation (can be paragraph, a picture or opening chapter) in which the narrator mentions about the setting of the story including characters, time and actions. 2. A complication that influence the plot of the story. 3. A sequences of event where characters react to complications 4. A resolution in which characters finally solve the 
complication, and 5. A coda (an optional stept) that provides a comment or moral value based on the story (p.8).

Anderson and Anderson (1997) state that: "language features in narrative texts include specific characteristics, time signal, action verb, and descriptive words"(p.17). A good narrative text employs descriptive words that can portray the appearance of characters (what they look like), the action (how things happen), and the setting (where the action takes place).

The reason why narrative texts are important is that they allow interactive processing to happen. In narrative texts, the stories are easy to understand. They are written in a simple structure in which the event happen after one to another. Thus, the stories can be read at once and the readers with minimum level of competence are able to follow (William et al., in NcNamara et.al. 2011:231-232). In contrast, expository texts involve complex structure and specific information that the readers in certain grades only are able to follow (Kamberelis and Bonivo in McNamara, 2011:231-232). Finally, narrative texts are written on various genres, namely humor, romance, crime, real-life fiction, historical fiction, mystery, fantasy, science fiction, diary-novel, and adventure. By choosing one of them, readers can get what they expect to know and extend their purpose of reading.

\subsection{A Grain of Wheat (1967)}

"A Grain of Wheat" was originally published in 1967, and was Thiong'o third novel. This novel portrays several characters in a village whose intertwined lives are transformed by the 1952-1960 emergencies in Kenya, as the action follows the villages' arrangements for Uhuru's (independence) day. The setting of the novel takes place in Kenya, mostly in and around a typical Kenyan village, which the writer calls Thabai. Thiongo writes about past and present events that make up the main story of the novel during the five days leading up to the country's first Independence Day celebration-8 to 12 December 1963. Most of the story is presented by using the flashback technique. Most of the characters are well developed and carried the same weight in the cause and effect of the storyline. The backdrop of the story is in Kenya when the country is on the verge of independence. Mugo is a poor orphaned man who had suffered a lot and is a pathetic to this, going on around him, and he expects the rest of the World to leave him alone. This happens until Kihika recruits him by force to join the rest of the freedom fighters. Resenting this, he betrays Kihika to the colonial government. 
Consequently, kihika is hanged and no one suspect Mugo to be the betrayer. In fact, people idolize him and see him as a hero. Unfortunately, it is Karanja, a man who collaborates with the colonialists and a home guard who become the main suspect and a number of people want to carry out their revenge on him, especially kihika's fellow freedom fighters Lt. koino and General R. Karanja and Gikonyo who were enemies due to their rivalry to Mumbi: Mumbi chooses Gikonyo, a carpenter, over Karanja. When Gikonyo is sent to prison by the colonial government like most men in the country, karanja sets out to seduce Mumbi who gives in and impregnated. On the other hand, the European in the country has their own devils to deal with.

John Thompson, at one time District office, and his wife Margery are considering leaving the country soon before the colonialist hand over power to the Africans. Unknown to Thompson, Margery was having an affair with Dr. Van Dyke, a meteorologist. Everyone knew apart from Thompson. The affair ended when Dr. Van was run over by a train. Dr. Lynd, a librarian, worked with Thompson and hated the Africans as she had one been attached and raped by them. She and her boyfriend Roger Mason were planning to leave to Uganda as soon as Kenya got its independence to avoid the blood killing they predicted would be meted out on all European by the Africans. When Gikonyo is released from prison he eagerly goes home looking forward to seeing Mumbi only to find her with Karanja as he was the new chief with immense powers he ignores Mumbi and mistreats her and she decides to leave for her parent's home. Meanwhile, as the Independence Day celebrations draw near, Mugo is pointed by the villagers to give a speech in honor of Kihika's memory, Mwauru is sent to Githima to lure Karanja to attend the celebrations as the freedom fighters intend to wring out the confession out of him before the crowd. Things take a turn when General R. asks for Kihika's betrayer and instead of Karanja, Mugo confesses. Everyone at the rally is shocked at the revelation. Karanja and Gikonyo's rivalry are brought to an end through a race that of them wins as they both tripped and fell with Gikonyo breaking his left arm. He is reconciled to Mumbi and Karanja leaves the village.

\subsection{A Grain of Wheat themes}

The main theme in the novel is the struggle for freedom against colonialism and racial discrimination."A Grain of Wheat" becomes a work of art as Thiong'o portrays realistic themes of colonialism and racial discrimination, and he shows the feeling of his people. He describes the Mau Mau movement and mentions people like Jomo Kenyatta. He makes use of symbolism. "A Grain of 
wheat" is the seed of rebellion which is represented by the Mau Mau. Kenya under colonial rule, unlike the average colony in Africa, was plagued with settler problems.

Consequently, the liberation struggle in Kenya was bound to be one of the most dramatics in the history of the continent. The freedom movement was the result of ills of colonialism affecting almost all tribes in Kenya. Their lands were taken away from them by the Europeans. Their education cut, their freedom curtailed through forced labour, their wages made miserably low and their pride and dignity trampled through disallowance of observance of tribal customs and rituals and finally through the practice of obnoxious color.

The most violent phase of the freedom movement occurred between the years 1952 and 1957. It all bagan when the most moderate demands made in 1951 were turned down by the British colonial government and a tougher attitude become apparent in the inner councils of the Africans. The basic reason had, of course, been the British government's policy of taking over the most fertile land from the Africans and givng it to the Europeans to cultivate. This led to a chronic shortage of land in the African reserves. As a result, thousands of umemployed youths were forced to work on European farms at miserably low wages and in appalling condition. This eventually leads to the rebellion movement and freedom from colonial rule.

\subsection{Biography of Ngugi WA Thiong'o}

Thiong's was one of the leading representatives of postcolonial theory in the World. He was born 1938 in Kamiriithu village, near Limura, Kiamble District, and the fifth child of the third of his father's four wives. A Kenyan dramatist, novelist, essayist, critic, scholar, cultural, social, and political activist, called "once of Africans most eminent literary figure", one of African's most articulate social critics"or in the similar way. However, in the World, he is probably best known of his novels at the time Kenya was under British rule, which ended in 1963.

Thiong'o belongs to the largest ethnic group of the Gikuyu tribe. His father, Thiong'o wa Nducu, was a peasant farmer, who was forced to become a squatter after the British imperial act of 1915. Thiong'o attended a mission -run school at Kamaandura in Limura district. However at school he also learned about the Gikuyu values and history and underwent the Gikuya rite of passage ceremony (Clifford Robson 1979:9). Later he changed his original name in 1976 from James Ngugi', which he saw as a sign of colonialism, to Ngugi wa Thiong'o in honor of his Gikuyu heritage. He left in 1964 for London entered Leeds 
University of London to pursue post graduate study, after he had received a Bachelor degree in English at Maker ere University in Kampala (Uganda) in 1963. Thiong'o worked as a journalist in Nairobi. The most prominent theme in his early work was the conflict between individual communities. Thiong'o is considered one of the East Africa's most eminent literary figure. Since the early 1960s, he has produced a number of novels, plays, and critical essay-both in English and Kenya's Gikuya language. He has made significant contribution to the African points of view and perspectives on life, politics, culture and history and his novels have earned him a well-deserved reputation that marks him out as a writer of the protest-literature.

In 1972, Thiong'o succeed Chinua Achebe as the new editor of African writer series, but soon discovered that his own writing was suffering under the huge responsibility of the editorship required (killam 2000: 5). It was during this period that he began to voice his anti- imperialist thoughts and tension started between him and the government of Kenya. Critics have consistently acknowledged Thiong'o as an important voice in Africa literature. He has been the voice of the Kenya people by certain commentators, while others have lauded his novels as among the most underrated and highest quality to come from Africa. Thiong'o's fiction has been noted for its overtly political agenda, its attempts to give a literary voice to the poor of the Kenyan, and its consistent criticism of colonialism and its oppressive regimes.

Critics have also praise his role as an influential colonial and post- colonial African writer. Howard (1973) believes that Thiong'o has decided to become more deeply involved in the social condition of his people. He further stresses that Ngugi involvement has been expanded to his day-today life as a Kenya. He is also on the opinion that "The River Between" (1965), "A Grain of Wheat"(1967), and "Weep not child" (1964) mark the return of Ngugi from Leeds University and shown that it would be as a new phase in his career"(p.103) It is clear that Thiong'o's works mostly center round the masses in the Kenya society.

Emenyonu and Oguzie (1989) say "Ngugi has become one of the greatest literary artists in Africa today, because of the skill and variety of his literary device. He recommended him for a long time for his literary skill" technically and aesthetically. "A Grain of Wheat", "Weep not child" and "The River between" reflect a decided change in Ngugi literary career"(p.3). With multiple points of view and fragmentation of narrative by chronological arrangement of event, A Grain of Wheat" bears the stamps of socialist influences. Nwankwo 
(1992:4) also argues that, the study of reading Thiong'o's works will not completed without an effect to understand how he arrived at certain kinds of preoccupation in his creative work (p.4). Thiong'o expresses himself in prose. His style is simple but conveys deep meaning and the crude reality of the people. It has a language of power, violence and patriarch. There is intrusion of the African language. He creates suspense throughout the novel which captivates the reader's attention. His style of writing is open ended, which leaves the reader to speculate and draw his own conclusion.

\section{RESEARCH METHODOLOGY}

This section outlines the methodology and describes the context of the present study with the aim of selecting the most appropriate research methods. The research methodology is also explored with the aim of creating and shaping the research design for the study. It examines how Thiong'o uses cohesive devices in "A Grain of Wheat". The analysis of the research is based on Halliday and Hasan (1976) cohesive model. The research design, data collection and data analysis are discussed and aligned with the research questions, aims and objectives of the study.

\subsection{Research Design}

The present study data source is Thiong'o's novel "A Grain of Wheat" in one volume format. In order to accomplish the announced objectives of the study, data assortment procedures have been carried out in line with its demands and limitation. This includes sorting out the text cohesive items according to their types, numbers of ties, distances, and the presupposed items.

\subsection{Data selection}

"A Grain of Wheat"(1967) by Ngugi wa Thiong'o was chosen for the sample of study. The study gives preference to the novel because of the qualities that Thiong'o possesses in writing this novel. He was born in Kenya and belongs to the Gikuyu tribe who suffered serious causality during the colonial era. $\mathrm{He}$ studied the norms, tradition and cultural rituals of his tribe and witnessed the colonial and post-colonial period in Kenya. He was educated at the colonial mission school and studied the Western Civilization. Therefore, he was able to reveal the reality of the events between the Gikuyu people and the British colonialists. The chosen text is greatly influenced by colonial /post-colonial era and has great impact upon the Gikuyu tribe in their society. Ngugi sees the disinheritance of their land as a real colonial omen which affected the people's psychological and metal growth.

\subsection{Procedure of analysis}


The study adopts Hatch's view (2002) which states that: "the design of qualitative projects must include a description of what the data of the study will be and how they will be collected "(p.53). To be able to gather the data accurately, the study employs the appropriate and suitable instruments in the research. In order to provide a systematic approach for the exploration of each novel and in keeping with the methodology, categories were the basic unit of analysis. According to Budd and Thorp (1963), categories are "classes into which material is grouped for the purposed of analysis"(p.10). If categories were to effective than they must be" (1) tailored accurately to fit the needs of the study so that they will provide answer to the questions asked (2) exhaustive (again relative to the questions under study, and (3) mutually exclusive"(p.10). The study is auto-employed as the prominent tool in collecting and analyzing the data in the natural setting, and planning and reporting the research analysis in accordance with the spirit of qualitative research to get the data in their natural setting. First of all, the original novel was read from chapter to chapter to find grammatical and lexical devices in context. The cohesive markers in the sample novel was taken systematically, one after the other. It was followed by note taking of the important materials of the data. As Leech and Short (1995) have pointed out, "it is impossible to select all the feature style in any particular text, and it is also difficult to analysis every single feature identified in the text" (p.10). The second step was taken by identifying or classifying the element of cohesion. All of them are subjected to analysis on the lexical and grammatical levels to find out how cohesion affects the discussion of social communication as portrayed by the novelist.

\subsection{Tool}

The study also uses computer software programma to calculate the numbers of cohesive ties in the novel.

\section{WordSmith}

Wordsmith tools is a softwere suite created by Mike Scott and consisting of three tools or application: wordlist, key words and Concord. For this three, the first one was used for the purposes of this study. Wordlist allows users to view the list of all the words occurring in the text.

\section{Application}

The corpus in this study was complied in four stages. The first stage involved visiting the websites. In the second stage, the text was copied into "words" sofeware document and arranged paragraph by paragraph in the order they appeared on the original page. In the third stage, the novel, was analyzed by 
identifying or classifying the elements of cohesion. Stage four involves the counting of the total number of each cohesive ties. The corpus was analyzed within the frameword of Halliday and Hasan (1976) model of cohesion. To answer the questions, the novel was analyzed around the clause and the corpus underwent an in-depth qualitative analysis, which revealed the grammatical and lexical features in question.

\section{Analysis of Grammatical and lexical cohesion as manifested in "A Grain of Wheat"(1967)}

The section of the study will focus mainly on analyszing grammatical and lexical cohesion as manifested in the novel written by Ngugi WA Thiong'o 1967. Cohesion is created by the author's selection of various lexical items and grammatical forms which act to tie a text together to form a single recognizable textual unit. The aim is to provide answer to the research questions, what kinds of cohesive devices are used in the novel? How do the grammatical and lexical cohesive devices integrate the sentences within the text? What are the dominant cohesive devices used by the author to deliver his message to the audiences about the struggle of the Kenya people to lebrate their country from colonialism and racialism? In order to answer these questions the study uses Halliday and Hasan (1976) theoretical framework which has been widely recognized by scholars and linguists. There are five classes of cohesive devices, which are: reference, substitution, ellipsis, conjunction and lexical cohesion. The following section will briefly introduce each device.

\subsection{Anaphoric reference}

Anaphoric reference is interpreted only by relating an item to something else a referent identical to it and preceding it in the text (Halliday and Hasan, 1976). For example:"Mugo felt nervous. He was lying on his back and looking at the roof" (A Grain of Wheat" p.1). The pronoun (He) is an anaphoric reference. It is a grammatical element referring to the hero Mugo.

\subsection{Cataphoric reference}

Cataphoric reference refers to any reference that "point forward" to information that will be presented later in the text (Halliday and Hasan, 1976).

Example: "Instead of buying chothes for himself or his family, Gokonyo did what Indian traders used to do (A Grain of Wheat; p: 63).

The word 'himself' or "his" is a cataphoric reference. It refers forward to "Gokonyo" in the second part of the sentence. Gikonyo is one of the major characters in the novel who fought to liberate Kenya from colonial rule.

\subsection{Personal reference}


Personal reference is a reference by means of function in the speech situation, through the category of person (Halliday and Hasan 1976:43). Personal references include possessive adjective, personal and possessive pronoun. For example: "We cannot let Kihika's name die. He will live in our memory and history will carry his name to our children in year to come" (A Grain of Wheat; p: 26). "We" is a personal pronoun." Our" is a possessive pronoun. "His" is a possessive adjective. In the sentence the personal pronoun "We" refers to the people of Kenya." Our memory" also refers to the memory of the Kenyan people. They would never forget the role played by the great hero kihika, who fought against British Colonialism and racial discrimination in Kenya. They will pass the message from generation to generation. Kihika is Mumbi's brother and a hero of the struggle. Someone in the village betrayed him to the British and he was hanged so he sacrificed his life for Kenya's freedom.

\subsection{Demonstrative reference}

According to Halliday and Hassan (1976:57), demonstrative reference is defined as a form of verbal pointing. The referent is identified by locating it on the scale of proximity. It uses words such as: this, that, these, those, here, and there. The examples from the novel illustrate demonstrative references:

\section{I tell you before the Emergency, I was like you: before the white man did} this to me with bullets, I could work with both hands, man (A Grain of Wheat: p.3). 2. The woman ruled the land of the Agokuyu. Men had no property they were only there to serve the whims and need of the woman. Those were hard years (A Grain of Wheat: P. 11).

Demonstrative reference, somehow, is used to represent a scale of quantity as well. The demonstrative reference "This" and "these" are used to point to things near the speaker. "This" represents a single thing such as phenomenon, pattern, stage etc. In sentence number one, the demonstrative reference (this) refers to the pattern used by the colonialist during the Emergency period to brutalize the African. Githua, a peasant of Thabai village was shot in his leg by a British soldier.He became paralyzed for the rest of his life. Whereas the demonstrative reference "these" is used to represent things in the amount of more than one things. In sentence number two above the demonstrative reference (these) refers to a large number of men who serve the whims and need of the Queen of (Agikuyu). 


\subsection{Comparative reference}

Comparative refrence refers to a type of reference that is used as a means of similarity or identity (Halliday and Hasan, 1976). General Comparion of difference is used when two or more things are in fact, the different thing. General comparison of identity is used when two or more things are in fact, the same thing. Meanwhile, both of the comparative and superlative are used to compare things between sentences. And particular comparison of numerative element is used to compare in terms of quantity.

Example: "Next to the carpenter was Mumbi, she was said to be one of the most beautiful women on all the eight ridges" (A Grain of Wheat; p: 15).

Adjective and adverb can be used to make comparison. They are used to show what is different or similar about two or more things. If the comparison is between three or more things then the superlative form must be used. Also, adjectives with three or more syllables form the superlative by putting the word "more" and "most" or "least" in front of the adjective as in the sentence above (the most beautiful women on all the eight ridges). Wumbi, is a symbol of the infected masses. Ngugi uses her to portray women in the society -their roles in the family, the society and the World. She was a victim of colonialism and racial discrimination.

\subsection{Substitution}

The second device the speakers or writers use to tie different parts of utterances to create sentences is substitution. Substitution involves the replacement of one item or items by another. Halliday and Hasan (1976) state that substitution is divided into three types: They are nominal substitution verbal substitution and clausal substitution.

\subsubsection{Nominal substitution}

In English, the most typical substituting word "one" or "ones" is often used in norminal substitution (Halliday and Hasan, 1976). Nominal substitution functions as a noun and can take the place of a nominal group. Example: "You see this panga needs a wooden hundle. The old one was burnt in the fire by mistake. My mother wants it quickly because it is the only one she has got for cultivating"(A Grain of Wheat; p: 88).

In this example, the substituting item "one" replaced "a wooden hundle". The cohesion in this sentence lies in the fact that there is a relationship between the substitute and the substituted element and so a link can be made between the two. The word "panga" refers to knife in Gikuyu language. This indicates that 
the Gikuyu people were farmers before their land was occupied by the British colonizer.

\subsubsection{Verbal substitution}

Verbal substitution was also evident in the novel. Verbal substitution operates as head of a verbal group e.g. do, does. (Halliday and Hasan, 1976). In the narrative, the verbal substitutes replaced the phrases that were mentioned previously in the novel. Example: "How do you know whether my playing is good or bad? You never come to the dances on Sunday'. Aah, true I never do. (A Grain of Wheat; P.85).

In this example, "do" substitutes "come ". The use of verbal substitution helps the writer from repetition. Regardless of the change of words, the message is still passed across. This shows how the cohesive device links the substitution to the substituted elements hence providing continuity of ideas within the text.

\subsubsection{Clausal substitution}

In this type of substitution, what is presupposed is not an element within the clause (so, not) (Halliday and Hasan, 1976). Example: Do you think that he was going to meet a woman? Koina now asked No, I don't think so (A Grain of Wheat; p: 29).

Here, (so) substitutes the clause (he was going to meet a woman). Koina was one of the Mau mau insurgent who fought against British colonialism in Kenya. He was conscripted as a cook during the Second World War. He is fiercely independent and bold.

\subsection{Ellipsis}

Halliday and Hasan (1976) define ellipsis as something left unsaid. However, it does not mean that what is unsaid is not understood. Ellipsis is closely related to substitution, which creates cohesive ties by omitting some parts of utterance. Ellipsis is also divided in nominal, verbal and clausal ellipsis. In ellipsis, the things left unsaid are usually understood by the hearer to mean something that had been mentioned earlier. On the semantic and structural level, ellipsis has often been treated as a device for creating cohesion in text. Brinton (1990) writes: ellipsis is standardly treated as a cohesive device because to supply or recover what has been omitted, the readers must take reference to a neighbouring clause, thereby forming a cohesive line...scheme of omission either from a structural link, by means of a gap in one segment or place connected elements side-by- side(pp: 182-184).

\subsubsection{Nominal ellipsis}


In nominal ellipsis, the thing, item, or person being reffered to is empty (Halliday and Hasan, 1976). It is a grammatical device where one slot in the grammatical structure is left empty. The lexical item omitted can then only be understood within context. Example: "who murdered your brother? Kihika "yes". The Whiteman (p. 201). In this example, the word "your brother" has been deleted. However, the omitted word can still be retrieved from the context and one is able to make sense of the sentence regardless of the omission. This makes the sentence cohesive as the omit word presupposes the previous word is not elliptical. Kihika is shown as the hero of the struggle. He was commited and strong. He made speeches which inspired the people to join the fight for freedom.

\subsubsection{Verbal ellipsis}

An elliptical verbal group presuppose one or more words from a previous group (Halliday and Hasan, (1976). There are instances of verbal ellipsis in the novel. Examples (a): Oh, carpenter, carpenter. So you know why I come? I don't (p: 86). Example (b): Did you suffer much? Mugo asked with sympathy. No. I do not (p: 74). The two verbal groups in answers ( I don't ) in (a) and ( I didn't) in (b), are both the instances of verbal ellipsis. Both stand for "I do not know" and there is no possibility of filling out with any other item. Author generally use ellipsis to indicate an omission of unnecessary words or information. Writers' use of ellipsis to build tension when it seems as though a character or the narrator is leaving something unfinished, or unsaid.

\subsubsection{Clausal ellipsis}

Clausal ellipsis in English, considered as the expression of the various speech functions, such as statement, question, response and so on (Halliday and Hasan, 1976). Example: "Why don't you people knock at the door before you rush in? He hissed at the man standing at the door. I knocked three times" (A Grain of Wheat p: 38). In this example, the answer to the question supposed to be'I knocked at the door three times, but the word is omitted to avoid repetition. The word "door" is omitted. Karanja goes to Mr. Thompson's house and Margery offers him coffee. The language that Margery and Dr. Lynd used against karanja after knocking at the door three times reveals their racism and prejudice. They make generalization about African people despite their limited experence.

\subsection{Conjunction}

Another way of maintaining cohesion is through the use of conjunction (Halliday and Hasan, 1976). Traditionally, it is believed that conjunctions do 
not only join sentences but also provide the reader with information for interpreting the sentences. Conjunctive elements are primarily devices to create cohesion by virtue of their specific meaning. It means that they express certain meanings and their meanings enable them to presuppose the presence of the other element. Therefore, conjunction is not only a matter of connecting two sentences, but also relating two events semantically. Conjunctions are classified into additive, adversative, causal, and temporal.

\subsubsection{Additive conjunction}

Additive conjunction is used for linking units of semantic similarity. The additive emphasize the key points or add relevant new information to the previous sentence (Halliday and Hasan, 1976).

Example:"The emergency destroyed us he said in a fearfful voice and abruptly went away (A Grain of Wheat p. 4). In this example, the conjunction "and" binds two sentences together. Githua was a villager who says that he lost his leg fighting in the struggle against colonialism and racial discrimination during the colonial era in Kenya. He meets Mugo and expresses a great concern over the destruction they face during the emergency period in Kenya. The two sentences are bound together as their content is similar, the first sentence addresses the destruction of the emergency period and the next about how Githua feels discouraged and went away. Therefore, the additive conjunction "and" shows how new information is connected to the old information. With this conjunction in place, it is believed that the interpretation of utterances become easier as the relation between is explicitly communicated. One does not have to guess how the sentences relate but instead, can follow through ideas presented by the conjunction with ease.

\subsubsection{Adversative conjunction}

Adversative conjunction is used to indicate information that mark correction, contrast, and opposite of the sentence mentioned previously (Halliday and Hasan, 1976). These are signaled by devices like, however, yet, but, nevertheless, althought etc. For example:

"A crowd of people waited outside the office of the M.P. because he was not in. But people were used to broken appointments and broken promises" (A Grain of Wheat: p: 67).

In this example, the adversative conjunction "but" shows contrast between the two sentences. The conjunction therefore presents a link between the first and second sentence by showing how the two sentences are related.

\subsubsection{Causal conjunction}


The function of causal conjunction is to express the sentence relationship between the cause and the result. The causal relation includes result, reason and purpose to form a cohesive chain. The clausal conjunctions are signaled by: so, so that, in order that etc. Halliday and Hasan (1976). Example: She had come to Kenya to do a job not to play politices. She liked the country and the climate and so had decided to stay (A Grain of Wheat; p: 50).

In this example, the causal conjunction in the sentence 'so' gives the reason why Dr. Lynd decides to stay in Kenya. The function of this conjunction is to indicate purpose. It also indicates the relationship that exist between the two sentences. Dr. Lynd was a research officer who traveled to Kenya during the colonial period. She was not involved in politics. The climatic condition of Kenya was good for her, so she decided to stay. Apparently, she had became the victim of the Africans' hatred towards the white people since, as she herself puts it, "she had never harmed anybody".

\subsubsection{Temporal conjunction}

Temporal conjunction is used to connect two sentences with sequential, simultaneous, or preceding relation in the text. It consists of; then, next, after, that, and so on (Halliday and Hasan, 1976). For Example: "In the name of Blackman's freedom, I salute you. Then, he bowed several times in comic deference (A Grain of Wheat; $\mathbf{p : ~} 3$ ). in this example, the temporal conjunction "then" shows how the order of events happened -revealing the sequence of events. Therefore, the conjunction indicates the relationship between the two sentences by specifying the order of events. Githua salute Mugo first, and later bowed several times. Temporal conjunctions are very important as they help the reader to order the events of different situation. With this conjunction in place, a reader can follow through in a systematic manner how things are arranged from the beginning to the end.

\subsection{Lexical cohesion as manifested in A Grain of Wheat (1967)}

Lexical cohesion is a linguistic device that is used to create unity among sentences. Lexical cohesion can be achieved through several devices such as repetition, synonymy, antonymy, hyponymy, meronymy and collocation. So, cohesion is partially expressed through using different types of vocabularies.

\subsection{Repetition}

Repetition is described by Hallday and Matthiessen (2004) as the most direct form of cohesion. Repetitionis the most direct source of lexical cohesion since it ties two identical lexical items. One lexical item is repeated in the same sentence or utterances in order to achieve unity of a text. Example: "They 
asked everybody to vote for party candidates in the coming election: a vote for the candidate was a vote for Kenyatta" (A Grain of Wheat; p: 71).In the example, Thoing'o uses repetition "to vote for the party", "a vote for the candidates" and "a vote for Kenyatta". The repetition of the word "vote" emphasizes to choose Jomo Kenyatta as their first president in order to free Kenya from colonialist's regime and racial discrimination. It is great importance to note that lexical repetition serves as a cohesive element in a text which connects sentences, paragrapha as well as fulfils the function of joining textual structure. It is one of a cohesive textual unit that significantly contributes to the structural organization of literary work.

\subsection{Synonymy}

Synonyms is one of types of reiteration in lexical cohesion. Synonyms can be verb, nouns, adverbs or adjectives, as long as both members of the pair are the same part of speech. The writer uses synonyms to express a similar meaning in another lexical word. Halliday and Hassan (1976) points out" Lexical cohesion results from the choice of a lexical item that it in some sense synonymous with a preceding one" (P.331).

For example: He tried to shut his eyes. They would not close. He tried to move his hand: it was firmly chained to the bed-frame (p.1). In the first example, the word (shut) is a synonymy of (close). "Fimly chained" is a synonymy of "to move" in the second sentence. The use of these lexical items show textuality of the text and allow the readers to easily understand the message.

\subsection{Antonymy}

Antonym is one of the types of reiteration where one items has contrast or opposite meaning to a preceding lexical word (Halliday and Hasan; 1976). The writer uses antonym to express an opposite meaning in another lexical word.

Example:

"General!" Warui exclaimed as soon as the new guests entered. Mugo walked backs behind the two men. One was tall, clean-shaven, with closecropped hair. The shorter man had his hair planned (A Grain of Wheat; p.22). Here, the word "tall" in the first sentence is the opposite of "short" in the second sentence. Hence, antonym heips English textual cohesion. Employing antonyms in text correctly reveals the oppositeness of the things and procedure the strong sense of camparison. Therefore, writers are fond of and are good at employing the antonyms in their literature works, and it contributes to achieve characterization, sense description, and statement of opinions, discussion and 
refutation. The linguistic study of antonym in Engish texts also help readers understand and appreciate author's intention much more easily. Every famous novelist without exception has a good master of antonyms.

\subsection{Hyponymy}

Hyponymy is one of the types of reiteration in lexical cohesion. Hyponymy is a relation of inclusion. (Halliday and Hasan; 1976) The application of hyponymy is that the writer uses of general class words. Example: "A neatly trimmed hedge of cider shrub surrounded the Thompsons' bungalow. At the entrance, green creepers coiled on a wood stand, massed into an arch at the top and then fell to the hedge at the side.The edge enclosed gardens of flowers: flame lilies, morning glory, sunflower, and bougain -villea (A Grain of Wheat; p: 41).

In this example, Thiong'o uses hyponyms to describe the beautiful flowers surrounding the villa of Mr. John Thompson. He was the administrative secretary during the colonial emergency period in Kenya. The garden around his house consisted of different flowers. Flame lily is a climbing herb with glossy leaves, enable it to use other plants to support. As the name goes, morning glory flowers are vines, which are souces -shaped, opening at morning. Sunflowers are helitropic, which means that they turn their flowers to follow the movement of the sun across the sky. Bougainvillea is a hardy tropical wine vine that grows in area where winter temperatures remain above 30 degree F (1c). In the sentence above, flame lily, sunflower, morning glory, and bourgainvilleo, are sub-division of flowers. Regardless of their differences in species, they are all natural in nature. The novelist uses these lexical items to create aesthetics in writing and link cohesive ties between sentences and paragraphs.

\subsection{Meronymy}

Meronymy refers to the lexical relation in which the relationship between two terms is one of "part -whole" or "whole part" (Halliday and Hasan; 1976). Much recent work in linguistics has focused on understanding the nature of semantic relations. Example: "He (Mugo) wanted to cover his eyes with his palms, but his hands, his feet, everything refused to obey his will... The blanket was hard and worn out; its bristles pricked his face, neck, in fact all the unclothed parts of his body "(A Grain of Wheat: p: 1). from the example, eyes, palm, hands feet, face and neck are meronymy of body. One can 
identify this relationship by using sentences frames like $\mathrm{X}$ is part of $\mathrm{Y}$, or $\mathrm{Y}$ has $\mathrm{X}$, as in eyes is part of the face, face has eyes. Palms is part of the hand, and hand is a meronymy of the body. The ability to use word meaning correctly and appropriately is an important part of linguistic compentence. The use of this lexical cohesive devices makes the whole texture more logical, developing from general to specific, and makes it easier for the audience to follow the writer's train of thought.

\subsection{Collocation}

Collocation describes the relationship between words that tend to co-occur. Halliday and Hassan (1976, p: 287) refer to them as a "general heading" or a "covering term". Collocation is the most problematic part of lexical cohesion, which is achieved through the association of lexical items that regulately cooccur. In other words, collocation is just a covering term for the cohesion that result from the co-occurance of lexical items that are in some way or another assoiated with one another in similar enviroments. Example:

\section{Gikonyu was among the first group of detainees to pass through the pipe -} line back to the village (p: 63).

In this example, the word "pass through" is collocation. It's consists of two words (pass) and (through), when combine together give different meaning. "Pass through" means undergo certain procedure by stages. It could also means to scrutinize. A notorious system of dentention camps called the "pipe-line' operated within the camps to hold Gikonyu suspected of having sworn on oath against colonialism. The colonial administration attached great importance to "black" detainees admitting to having taken an oath. If he did, he was categorized as "grey" and moved up the pipeline leader (Anderson 2005), although his treatment remained equally brutal. Gikonyu was one of the detainees to undergo the pipeline procedure during the Emergency period in Kenya. 
Cohesion in African Narrative: A Linguistic Study of Racial Discrimination and Colonialism in A Grain of Wheat by Ngugi WA Thiong'
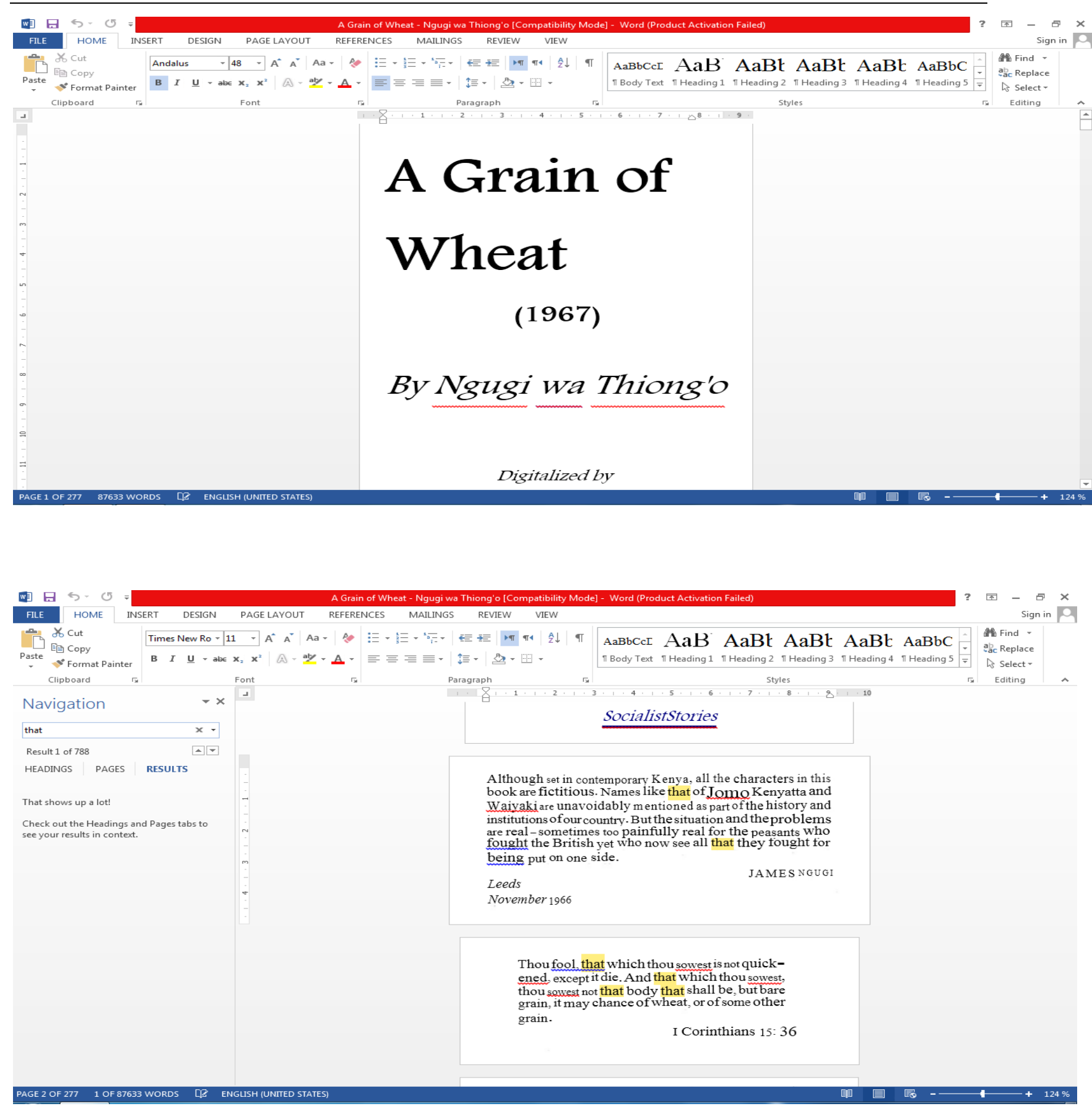

APPLICATION OF SOFTWARE COMPUTER PROGRAMM TO COUNT THE NUMBERS OF FREQUENCIES IN "A GRAIN OF WHEAT"

Percentage of Grammatical and lexical cohesive devices in "A Grain of Wheat"(1967)

\begin{tabular}{|l|l|c|}
\hline No & Grammatical & Frequency (\%) \\
\hline & Reference & $\mathbf{3 4 3 2 0}$ \\
\hline $\mathbf{1}$ & Endophoric reference & $0,15 \%$ \\
\hline $\mathbf{2}$ & Anaphoric reference & $43,37 \%$ \\
\hline
\end{tabular}


Cohesion in African Narrative: A Linguistic Study of Racial Discrimination and Colonialism in A Grain of Wheat by Ngugi WA Thiong'

\begin{tabular}{|l|l|c|}
\hline $\mathbf{3}$ & Cataphoric reference & $19,22 \%$ \\
\hline $\mathbf{4}$ & Personal reference & $5,44 \&$ \\
\hline $\mathbf{5}$ & Demonstrative reference & $27,60 \%$ \\
\hline $\mathbf{6}$ & Comparative reference & $4,22 \%$ \\
\hline & Substitution & $\mathbf{2 6 4 3}$ \\
\hline $\mathbf{7}$ & Nominal substitution & $31,44 \%$ \\
\hline $\mathbf{8}$ & Verbal substitution & $27,54 \%$ \\
\hline $\mathbf{9}$ & Clausal substitution & $41,01 \%$ \\
\hline & Ellipsis & $\mathbf{2 3 4}$ \\
\hline $\mathbf{1 0}$ & Nominal ellipsis & $41,03 \%$ \\
\hline $\mathbf{1 1}$ & Verbal ellipsis & $30,34 \%$ \\
\hline $\mathbf{1 2}$ & Clausal ellipsis & $28,63 \%$ \\
\hline & & $\mathbf{7 9 9 2}$ \\
\hline & Conjunction & $42,15 \%$ \\
\hline $\mathbf{1 3}$ & Additive conjunction & $10,14 \%$ \\
\hline $\mathbf{1 4}$ & Adversative conjunction & $15,64 \%$ \\
\hline $\mathbf{1 5}$ & Temporal conjunction & $32,07 \%$ \\
\hline $\mathbf{1 6}$ & Causal conjunction & $\mathbf{4 1 6 2}$ \\
\hline & Lexical cohesion & $19,21 \%$ \\
\hline $\mathbf{1 7}$ & Repetition & $12,60 \%$ \\
\hline $\mathbf{1 8}$ & Synonymy & $13,09 \%$ \\
\hline $\mathbf{1 9}$ & Antonymy & $11,77 \%$ \\
\hline $\mathbf{2 0}$ & Hyponymy & $29,06 \%$ \\
\hline $\mathbf{2 1}$ & Meronymy & \\
\hline $\mathbf{2 2}$ & Collocation & \\
\hline & & \\
\hline
\end{tabular}

\section{Finding and conclusion}

The analysis of the novel revealed that both grammatical and lexical cohesive ties are used. Analyzing the corpus reveals that reference, among other cohesive devices, prevails in the novel with the frequency of (34320). This extensive employment of reference can be attributed to the fact, as Halliday and Hasan (1976) illustrate, that reference is potentially cohesive because the thing that serve as the source of interpretation may be an element of the text. Reference belongs to the literary type of language as it creates emphasis or sense of participation. As a cohesive device, reference helps in making the text more condensed and understandable. 
Although Grammatical and lexical types have an approximate occurrence in the data, their subcategories vary. The grammatical cohesion was found to be slightly higher in terms of frequency of occurrence than those of lexical cohesion. On the grammatical level, the highest frequency goes to the cohesive ties of reference which provides a sense of identifiability in the narrative text. Among the reference cohesive ties, anaphoric reference held the highest frequency (43.37\%). Cataphoric reference, on the other hand constitutes (19.22\%). Demonstrative reference appears to be the second most frequent type (27.54\%). The use of these demonstrative references as a cohesive device show the specification of items in various places and communicates their meanings in a unified way to create the whole semantic web of the novel. Personal and comparative cohesive ties carried the second lowest frequency as manifested on the table. Personal reference constitutes (5.44\%), whereas comparative reference is $(4.22 \%)$. Endophoric reference is the least $(0.5 \%)$.

The analysis reveals that the novel contains all types of references: endophoric, cataphoric, anaphoric, personal, demonstrative and comparative reference. However, the numbers of instances of these references vary. Comparative reference links the information comparatively both in anaphoric and cataphoric ways to strengthen the semantic connectivity and the texturing unity of a text. These references help avoid repetition and provide the text with semantic unity which increases the interest of readers. Anaphoric and cataphoric references connect the information in the text and provide a unification of meaning.

Other grammatical cohesive devices are substitution and ellipsis. Substitution constitutes the total number of (2643) as shows in the table. Clausal substitution ranks as the highest with $(41.01 \%)$. While Nominal substitution stands as the second as being of (31.44\%). Verbal substitution on the other hand, carries the least with $(27.54 \%)$ from the grand total. In the case of ellipsis, as the analysis shows, represents the total number of (234) as a whole. Nomilal ellipsis shows the highest $(41.03 \%)$, and it follows by verbal ellipsis with $(30.34 \%)$. Clausal ellipsis stands the least positon of all with $(28.63 \%)$. The use of substitution and ellipsis as cohesive sources brings conciseness in the semantic texture of the text and locks its cohesive structure in a united whole. Both these devices bring semantic authenticity, variety, and connectivity and bound different grammatical and lexical items in the text. The analysis reveals that these devices play an important part in creating a precise and semantically unified text.

In terms of the cohesive conjunction, as the table presents, this device has been accounted as (7992). The percentage varies among the four subtypes of 
additive, adversative, temporal, and causal. The hightest share is registered to the additive subcategory as being of $(42.15 \%)$. Causal conjunctives wins the second ranks of (32.07\%), and temporal subscategory ranks as the third $(15.64 \%)$. Whereas, adversative substype stands as the lowest frequent with just (10.14\%) from the total. Looking at the various uses of these subcategories, the study notices that the novelist uses them to provide transitions within the novel to serve narration and dialogue. Through this means, he controls the demands of discourse meaning continuity and plot progress. These devices facilitate in maintaining the communication sequence of the characters, integrate the textual information, and enrich the semantic texture of the narrative.

Lexical cohesive devices are of crucial important in the novel as they take the role of organizing the text and rendering it cohesive. Lexical cohesion, as one of the most important aspects of literary texts, must be highlighted due to its evident contribution to the establishment of the aesthetic effect of the text. In term of lexical cohesion, the two main subcategories are analyzed namely reiteration and collocation. Furthermore, reiteration has been tackled under five subtypes as: repetition, synonmym, antonymy, hyponymy and meronymy. As stated in the table, lexical cohesion accounted as (4162) ties. Collocation is the hightest frequent one $(29.06 \%)$, followed by repetition $(19.21 \%)$, and the third rank goes to synonymy (17.60\%).hyponymy carries the fourth ranks with $(11.77 \%)$. Antonymy takes the fifth position of (13.09\%), and meronymy marked as the lowest with $(9.27 \%)$.

Lexical cohesion in "A Grain of Wheat" (1967) provides the semantic harmony to the text. The repetition of certain vocabulary items make their complete semantic circle and help in texturing the unified semantic structure. The repetition of the same lexical items also hightlights their significance place in the overall lexical stock of the text and renovates its meaningful part in portraying the thematic outlook of the text. The accumulated information structured in the text in the form of superordinates gives an extensive explanation to one semantic unit with a variety of terms, systematically classifies the semantically connected terms, and organizes them into separate semantic entities at the same time which then as a whole get cohesively linked into a whole semantically united structure.

The use of collocations in the text is another form of lexical binding that integrates the related pairs of meanings and enrich the connotative and denotative semantic bases. Collocated information, in the novel, set itself in line with the structural infrastructure of information patterns and forms a 
grammatical and semantic linking with the cohesive harmony of the whole text. In other words, lexical cohesive devices contribute to the application and specification of the meaning of the narrative text by offering the readers multiple choice of interpretations which lead to the establishment of interconnected text. Halliday and Hassan (1976) made it clear that lexical cohesive devices are the most stable way of pointing to the same referent and as such contribution to the maintenance of a cohesive text.

The analysis also revealed that as African writer, Thing'o is committed to probing into the structures of colonialism and racial discrimination. He does this by proving that the native characters are discriminated against because of their color. The blackness is discriminated against because of the race. The white race is empowered by their skin color to exert power over the blacks even though the blacks are the majority. The racial discrimination spans from lands, for blacks and whites, specific job description for white and blacks separate restaurants for blacks and whites, special laws for blacks to special economic ventures for blacks.

Thiong'o is successful by using grammatical and lexical cohesive devices to portray the evil act of colonialism and racial discrimination. He excels at showing the role played by white settlers in constructing colonialism and racial discrimination ideologies. In Kenya colony, the British were segregating the natives into the worst and least habitable parts of their own land. Once the good land was vacated by the Africans, the whites seized it for themselves. The white in Kenya established a government based on white suffrage. Not only were the Africans denied participation in the colonial government, a sizeable contingent of East Indian laborers could not have any decisive voice in the government nor could the Indians develop many of the choicest farmland. The land and the government were solely the white man's domin. DuBois (1924) summed up the entire British effect in Kenya effort in the Kenya colony with the following prophetic statement: It is an attempt to found white supremacy in African ...It will never succeed but it will cause endless bloodshed and misery before it fails" (P. 151-52).

\section{Conclusion}

The application of the cohesion model on "A Grain of Wheat" had highlighted the sequential track in the text that not only systematically infers the unity of meaning in this text but also gives practical understanding in generating such integrated text. The analysis reveals, in Thiong'o's work, that each device works in correlation with this semantic processing and coins an elemental semantic 
linkage with the previous one as the one presupposes and the other is presupposed. This dispensation is achieved by describing backward and forward semantic connections. The study will add up to the fundamental linguistic knowledge of both learners and teachers with the perspective of richness in interpreting the textual data along with keeping in line the whole semantic connectivity of a text. The applied model of cohesion can also be used as a teaching model with a specific focus on lexica-grammatical basis of English to enhance the identification of multiple meanings and structuring of semantically unified and cohesive text. Furthermore, the knowledge of cohesion is indispensible for a complete textual understanding and perfect knitting of ideas.

\section{References}

Thing'o. W. Ngugi (1967)." A Grain of Wheat": Heinemann print.

Abrams, M. (1999). A Glossary of Literary Terms. Australia: Heinle and Heinle.

Anderson, M. \& Anderson, K. (1997). Types 1. South Yarra: Macmillan Education. Australia. Piy LTD.

Ania, L. (2005). Colonialism and/ post colonialism. Note 27: p. 5).

Bae, J. (2001). Cohesion and Coherence in Children's writing English: immerron and English -only classes. Issues in applied Linguistics. Vol.12 (1). Pp.51-88.

Barkute, D. (2005). Inter-sentential Anaphoric use of personal pronoun English Discourse. Kalbatyla, 55(3), 1-7 Retrieved Jun 26, 2011.

Block. B. \& Trager, G. L. (1942). Outline of Linguistic Analysis. Baltimore: Linguistic Society of America/ Waven. Press

Britton, K.B. (1994)."The Development of Discourse markers in English" Journal of Historical linquistics and Philosophy. J. Fisia (Ed). Germany, Berline: Walter de Gruyter, pp.45-71).

Bloor, T. \& Blood, M. (1995). The Functional Analysis of English. D. Schriffin, D. Tannen \& H. E. Hamilton (Ed). The Handbook of Discourse Anaysis: Arnord.Blackwell publishers Ltd (le, 2001), London.

Budd, R. W. and Throp, R. k. (1983). An Introduction to Content Analysis Iowa City. IA: University of Iowa press.

Block. B. \& Trager, G. L. (1942). Outline of Linguistic Analysis. Baltimore: Linguistic Society of America/ Waven. Press. 
Brown, G. \& Yule, G. (1983). Discourse Analysis. Cambridge: Cambridge university press.

Chomsky, N. (1965). Aspect of the Theory of Syntax. Cambridge; Mass: Mit press.

Crystal. D. (1992). The Cambridge Encyclopedia of language, Cambridge university press, Cambridge.

Eggins, S. (1994). An Introduction to Systematic Functional Linguistics; $2^{\text {nd }}$ ed. London:

Continuum. New York.

Emenyonu, E. (1995). "Literature in a Second Language", Use of English in Nigeria Fiction" in Bamgbase A. et al (Ed) op cit.

Fowler, R. R Hodge, G. Kress and T. Trew (1997). Language and Control. London: Routledge and Kegan Paul.

Fiske, S.T. (2010). Interpersonal stratification: status, power and subordination, in Fiske, S. T.Gilbert, D. T.Lindzey, D. (Eds). Handbook of social psychology, fifth ed. Wiley, New York.

Fludernik, M. (2006). An Introduction to Narratology. London and New York: Routledge, pp.x+190 ISBN: 415450292.

Gee, J. (1999). An Introduction to Discourse Analysis: Theory and Method. London: Routldge

Gutwinski. W. (1976). Cohesion in literary text: A study of some grammatical and lexical features of English Discourse. The Hugue/ Paris: Mouton

Graham, A. (2000). Intertextuality London: Rutledge Taylor: Pluto press.

Guy, C. (1989). Discourse, London: Oxford University Press. London Hatch, J. A. (2002). Doing Qualitative Research in Education setting; Albany state University: New York press.

Hall, R. A. (1968). An Essay on Language Philadelphia: Chilton Books.

Halliday, M.A. K. and Regalia, H. (1985).Language context, and text: Aspect of Language in a social-semiotic perspective. Victoria: Dakin University press.

Halliday, M. A. K. (1994). An Introduction to Functional Grammar ( $\left.2^{\text {nd }} E d\right)$. London: Edward Arnold.

Halliday, M. A. K. \& Jonathan, W. (2006). On Language and Linguistic Continuum. International Publishing Group P. Vii. ISBN 0-8264-8824-2.

Halliday M. Hasan R. (1976). Cohesion in English: London: Longman.

Halliday, M. Hasan R. (1976). Language Context and Text: Aspects of Language in Social-Semiotic Perspective ( $2^{\text {nd }}$ Ed) Oxford: Oxford University Press. 
Halliday M. Hasan, R. (2013). Cohesion in English -USA: Rutledge Retrieved May 3, 2014.

Halliday. M.A.K. and Mathiessen. C. (2004). Introduction to Functional Grammar London: Arnold Edward.

Hasan, R. (1984), Coherence and Cohesive harmony-In J. Flood (Ed), Understanding Reading comprehension, (pp.181-219), Delaware: International Reading Association.

Hasan, R., (1986b) 'coherence and cohesive hormony: InJ. Flood (Ed) understanding Reading comprehension (Netwart, Del: IRA). PP.181-221.

Hasan, R. (I985), Linguistics, Language and Verbal Art (Geolong, Vic: Deakin University Press).

Halliday, M.A. K. and Regalia, H. (1985).Language context, and text: Aspect of Language in a social-semiotic perspective. Victoria: Dakin University press.

Halliday, M. A. K. (1994). An Introduction to Functional Grammar ( $\left.2^{\text {nd }} E d\right)$. London: Edward Arnold.

Heigham, J. Croker, R. Eds (2009).Qualitative Research in Applied Linguistics. A Practical Introduction: Palgrave Macmillan.

Hoey, M. (1983). On the Surface of Discourse. London: George Allen and Unwin.

Jabeen, I. Mehmood, A. and Iqbal, M. (2013). Ellipsis, reference and substitution as cohesive device: the bear by Auton Cheklov, Academic Research International, 4/ (6), 123-131.

Kaur, S. (2015). A study of cohesion devices in John Keats' "Ode to autumn". Modern Research studies, vol. 2(1), pp. 134-143.

Leech. G.N. and Short. M. H. (2001). Style and fiction. (2 ${ }^{\text {nd }}$ Ed) Pearson Education Ltd.

McNamara, D. S. Crossley, S.A. \& McCarthy, P. M. (2010). Linguistic Features of writing Quality. Writing Communication, 27(57), 24.

Ogude, J. (1999). Ngugi's Novels and Africa History; Narrating the Nation. London: Pluto Press.

Sapir (1921), Language (An Introduction to the study of Speech): Harcourt, Brace the University of Michigan.

Syal, p. and Jindal D. (2011). An introduction to linguistics: Language, Grammar and semantics -New Delhi: practice Hall of India.

Thompson, G. (2006). Introducing Functional Grammar: $2^{\text {nd }}$ ed. London: Hodder Arnold Publication. 
Verikaite, D. (1999).Formal and Functional characteristics of cohesive devices in the science research article in English. Abstract of Doctoral Dissertation. Vihus: VPU

Witte, S. P. \& Faigley, L. (1981). Coherence, Cohesion, and Writing quality. College composition and communication, 32, May 189-204.

Williams, P. (1998). Ngugi WA Thiong'o. Manchester and New York: Manchester.

Yde. P. and Spoelders, M. (1985). Text cohesion and Exploratory study with beginning writers; applied Psycholinguistics. 6. 407-41.15. 